\title{
THE IMPLEMENTATION OF E-MORTGAGE IN RUSSIA \\ ON THE EXAMPLE OF THE UNITED STATES
}

\section{${ }^{1}$ R. Pshenichnov, ${ }^{2}$ A. Burkov}

\section{Abstract}

Like any other industry, the mortgage market doesn't stand in one place. With the development of electronic technologies, banks have the opportunity to make their services more accessible. The possibility of applying for e-mortgage will be legislated in 2018. This could have a positive impact on the mortgage market or not have success. This article shows the analysis of the implementation of electronic registration in the United States. As of February 2015, there have been 338 thousand mortgage loans in electronic format since 2005 , which is less than $30 \%$ of mortgage loans in one year. These figures on the US market reflect wrong actions of this country during the process of e-mortgages implementation. Based on the data of the study there were recommendations made for the introduction of electronic registration in Russia.

Keywords: mortgage, banking, electronic mortgage, electronic mortgages, electronic Commerce.

На данный момент Российская экономика постепенно выходит из кризиса. Не исключением является и банковский сектор. Сложные, кризисные, годы привели к усилению конкуренции на ипотечном рынке. Нежелание терять долю рынка привело к резкому снижению ставок по ипотеке. Для сохранения маржи банки были вынуждены оптимизировать свои расходы. Для этой цели большинство банков применили стандартные инструменты: сокращение численности сотрудников и количества офисов. В основном сокращения не привели к потере доли рынка за счет замены людей искусственным интеллектом и переводом операций в формат электронной коммерции.

Изменения в работе банков почувствовали не только внешние клиенты, но и внутренние. Лидером инноваций в сфере продажи услуг через удаленные каналы обслуживания на ипотечном рынке России является ПАО Сбербанк. Только в данной организации есть возможность оформления ипотечного кредита за одно посещение офиса банка. Все этапы взятия ипотеки до подписания кредитной документации можно осуществить через личный кабинет заемщика: подать заявку на ипотеку, выбрать объект недвижимости или риелтора, загрузить документы по объекту недвижимости, оформить страховку, рассчитать ежемесячный платеж и дополнительные расходы, консультироваться в режиме онлайн со своим менеджером по ипотечному кредитованию. После одобрения объекта, клиенты мо-

${ }^{1}$ Ruslan Pshenichnov, post-graduate student, Mari State University, Russia.

${ }^{2}$ Aleksey Burkov, Doctor of Economics, Associate Professor, Professor of the Department of Applied Statistics and Informatics, Mari State University, Russia. 
гут оформить кредит, зарегистрировать документы в Росреестре и рассчитаться с продавцом за одно посещение банка за счет оформления услуг «Электронной регистрации» и «Системы безопасных расчётов». Внедрение данных услуг показало потребность среди населения по внедрению подобных сервисов. Следующий шаг, который позволит Российской банковской системе выйти на новый уровень обслуживания - это электронное оформление ипотечных сделок.

К сожалению, у нас в стране нет достаточной гражданско-правовой базы для внедрения электронной ипотеки, но в скором времени она появится. Президент Российской Федерации Владимир Владимирович Путин 25 ноября 2017 года подписал Федеральный закон №328-Ф3 «0 внесении изменений в Федеральный закон «Об ипотеке (залоге недвижимости)» и отдельные законодательные акты Российской Федерации», который вводит в оборот электронную ипотечную закладную.[1] Электронная закладная позволит перейти на полностью электронный документооборот при покупке жилья в ипотеку. Это позволит сократить расходы банков, будет способствовать дальнейшему снижению ставок по ипотечным кредитам, упростит секьюритизацию, за счет чего снизится нагрузка на капитал банков и будет способствовать долгосрочному фондированию.

В мире уже существуют системы получения ипотеки в электронном формате. Соединенные Штаты Америки являются первой страной, внедрившей электронное оформление ипотечных кредитов. Принятые в 2000 году законы о ЭЦП и цифровых актах приемки-передачи позволили данной стране перевести все процессы и документы в цифровой формат. Для продажи ипотечных пулов используется «Система Электронной Регистрации Ипотеки» (Mortgage Electronic Registration Systems), которая позволяет выполнить обязательное требование Fannie Мае или Freddie Mac (агентства покупающие долговые обязательства заемщиков по ипотечным кредитам). MERS является частной компанией, принадлежащей участникам рынка.

Плюсами электронной ипотеки в США являются:

1.Снижение срока закрытия сделки - по оценке Fannie Mae внедрение электронного формата ипотечной сделки позволит снизить продолжительность сделки с 52 до 22 дней. Согласно исследованию PwC, 84\% заемщиков хотели бы ускорить процесс закрытия сделки, 48\% назвали желаемый срок от 2 до 4 недель, 38\% - менее двух недель.

2. Улучшение удобства заемщиков - электронный формат ипотеки это естественный формат эволюции с точки зрения потребителя. Клиенты сегодня хотят прозрачность, удобство использования и доступ в реальном времени во всем, что связано с финансовыми транзакциями и ипотека не исключение.

3.Снижение расходов на закрытие сделки - по оценке Ассоциации Ипотечных Банкиров использование электронного формата поможет снизить расходы в среднем на $\$ 1100$ с каждой сделки, что приведет к ежегодной экономии в \$1 млрд в масштабах всей индустрии. 
К сожалению, опыт США показывает, что у электронной ипотеки существуют большие проблемы с внедрением данной технологии. По состоянию на февраль 2015 г. всего, с 2005 г., было выдано 338 тыс. ипотечных кредитов в электронном формате, что составляет менее $30 \%$ от выдачи ипотеки за один год.

Причинами низкой доли оформления электронных ипотек в США являются следующие факторы:

1.Недостаток необходимой инфраструктуры (нотариата, титульных агентов), единых стандартов рынка, дороговизна и сложность перехода.

2.0тсутствие вторичного рынка электронных закладных, кроме агентств их никто покупает.

3.Недостаток предложения со стороны оптовых кредиторов.

4.Дороговизна и сложность технологий.

5.Сложности с обучением персонала.

На основе данных исследования, при внедрении электронной ипотеки в России необходимо одновременно развивать следующие направления:

1.Внедрять цифровые финансовые паспорта заемщиков, которые позволят заемщику максимально быстро подавать заявку на ипотечный кредит, а кредитору ее обрабатывать. В России уже пытались создать аналогичный проект по введению УЭК, но он не был реализован по техническим причинам.

2.Предоставлять услуги по хранению закладных. Электронные хранилища закладных требуют значительных инвестиций, и многие участники рынка предпочли бы аутсорсить эту функцию. Наиболее оптимальный вариант, если государство возьмет на себя эту функцию, включив расходы в госпошлину по регистрации.

3. Создать национальный регистратор. Несмотря на то, что MERS принадлежит участникам рынка, это частная компания и многим не ясно, что будет с электронными закладными в случае ее банкротства. Необходимо изначально делегировать данную функцию Росреестру.

References:

[1] E-mortgage mortgage will be used from 1 July 2018. (27 November 2017). Received 30 December 2017 from the House.Russia: https://дом.рф/2017/11/27/elektronnaya-ipotechnaya-zakladnaya-nachnetispolzovatsya-s-1-iyulya-2018-goda/

[2] Zuev, A. V. (2013). The development of mortgage lending in the Russian Federation the prospects and problems of development. Innovation and investment(5), pp. 133136.

[3] Ivashina, V. E. (2016). The impact of government subsidies on mortgage lending in the Russian Federation. Individual entrepreneur Kuzmin Sergey Vladimirovich(11 (35)), pp. 201-207.

[4] Korosteleva, T. S. (2016). Mortgage lending as a factor of intensification of the growth of regional ecosystems (based on materials of Samara region). The housing strategy, 3(4), pp. 279-298.

[5] Korotaeva, N. V. (2015). Analysis of the current state of the Russian mortgage market: development trends. Socio-economic phenomena and processes, 10(10), pp. 70-75. 
$6^{\text {th }}$ International Conference

«Science and practice: a new level of integration in the modern world» 